\title{
REPRESENTING RADIATION RISK
}

\author{
// OLGA BLOEMEN
}

WITH PHOTOGRAPHY BY

DARREN NISBETT //

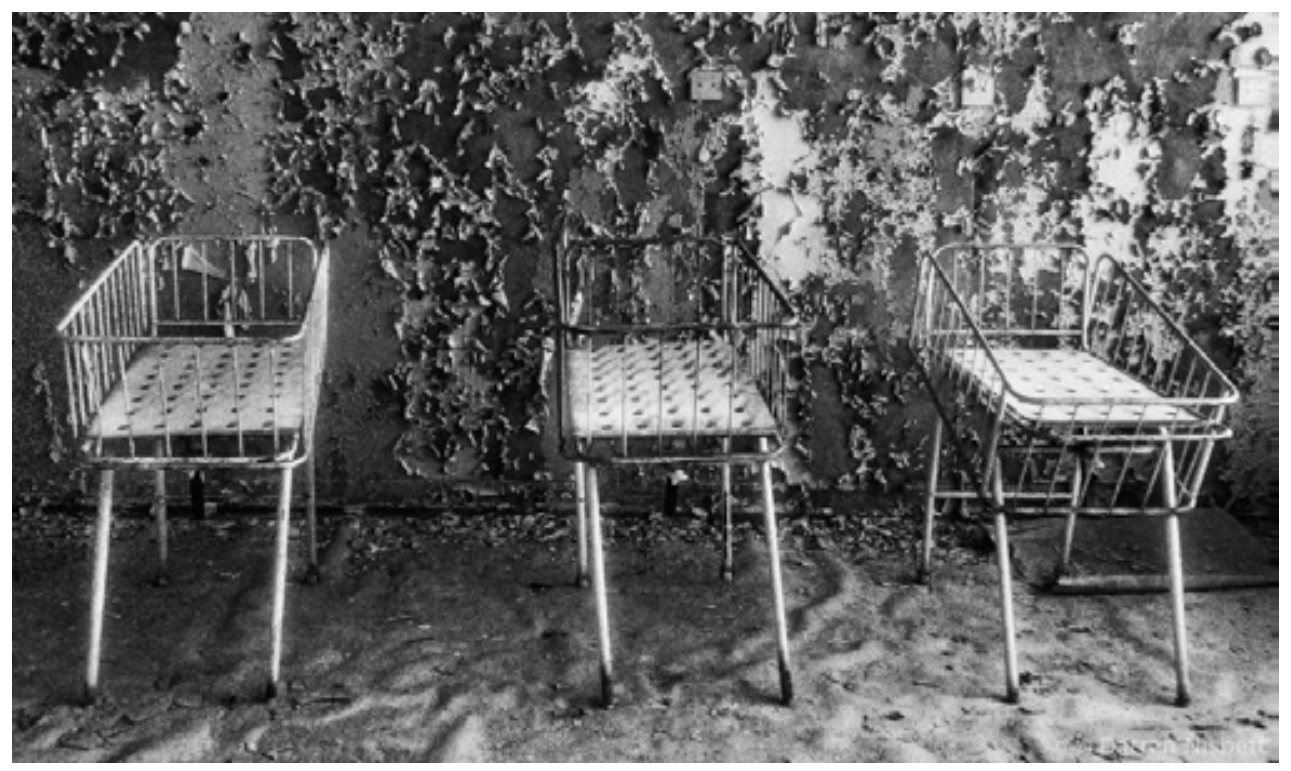

'Bedtime Stories'

radioactivity |,rādēōak' tivətē|

noun

the emission of ionizing radiation or particles caused by the spontaneous disintegration of atomic nuclei. 
onsisting of moving subatomic particles, radioactiv$\checkmark$ ity is invisible, has no smell and makes no sound. Its presence can only be detected with Geiger counters and other measuring instruments. Its transformations and symptoms are more real to us: the iconic mushroom cloud of a nuclear bomb, barrels of nuclear waste, cancer increases in exposed populations, or contaminated wastelands. Recognition of radioactive risk, or its denial, depends on those who employ the measuring instruments, assess cancer or toxicity rates, or set safety standards. In a society greatly relying on empirical evidence and technical expertise, it is scientists who have first access to knowledge about radioactivity.

\section{NATURE'S REPRESENTATIVES}

With the birth of modern empirical science, scientists have come to be seen as representatives of an entity called 'nature' (see Latour 2004). The perceived separation between nature and culture fuelled expectations of 'nature' as tractable and promised human flourishing through scientific and technological progress. These beliefs were challenged with the rise of environmentalism and public awareness of risks, before but significantly since the 1960s. However, as environmentalism became more integrated in 'mainstream' political institutions, science and technology were again elevated as the solution to 'environmental issues' rather than part of the problem (see Grove-White 1993, Yearly 1993). In the development and implementation of recent environmental policies and regulations, scientific experts are front and centre.

Two quotes taken from web-articles on the nuclear disaster in Fukushima in March 2011 exemplify this:

But just how much [nuclear] fallout does the government need to remove in order to protect human health? On that key question the science is frustratingly inconclusive. [Bird 2012, my emphasis]

'What impact this radioactive contamination has on marine life and humans is still unclear... this is not a fully developed science and there are lots of uncertainties.' [Grozman 2011, my emphasis]

Implicit here is the expectation that science, if 'fully developed', should be able to provide conclusive evidence on matters like the impact of radioactivity. As will become clear, scientists walk a tight rope: they need to balance the high uncertainties in their knowledge with the high demands for facts from policy-makers, industry and members of the public. At the same time, the (empirical) is question is tied up with the (normative) ought question: what impacts of nuclear technologies are acceptable, or in other words, to what extent should human and environmental health be compromised under the banner of technological and social progress?

In September 2012, I conducted fieldwork at the 'International Symposium on Environmental Radioactivity: Implications for Environmental \& Human Health' in Plymouth, England. Speaking to radio-epidemiologists, radio-biologists, radio-ecologists, radio-chemists, radiophysicists, geo-chemists and geologists, as well as to policymakers and members of industry, I tried to gain access to otherwise secluded knowledge about environmental radioactivity.

\section{ORDINARINESS}

The church-turned-conference venue at the edge of Plymouth's University campus was characterised by swiftgliding doors and a lack of natural light. The programme of the conference was packed with presentations, mostly concerning pieces of research, case studies and protection frameworks. The socio-political dimensions of environmental radioactivity were packed into six presentations in the last session, with the mouthful title of 'Regulation, Policy and Risk Assessment; Research Need; Socio-Economic Impact; Public Perception'.

In the mornings and soon after lunch, only the front benches of the lecture theatre were filled. Many of the senior researchers seemed to know each other ('It's a small field', I was told) and used the gathering mainly for meetings and catch-ups. PhD students admitted to be hunting jobs, while delegates from industry and policy stayed on the fringes. Differences were smoothed out, however, on the evening of the first day, when I accompanied the delegates to a fancy fish dinner in the National Marine Aquarium. Rays and small sharks witnessed us from behind the glass wall while wine was being generously poured.

For most of it, the symposium stood out in its appearance of ordinariness. A visit of a local journalist to the welcome reception was the only indication that the conference topic was of any public importance. But the devil, as always, was in the detail - or, perhaps, in the discourse.

\section{DEFINITIONAL STRUGGLES}

Taking a Foucauldian discursive approach, scientific discourses can be seen as 'normalising discourses' whose power lies both in their ability to define experience in a particular way and to efface this particularity and their underpinning power relations by framing these as natural. Scientific definitions of, for example, risk, pollution and harm partly determine how people perceive and interact with the environment.

In the field of environmental radioactivity, however, scientists are constantly challenged in their role as authorised representatives of radiation risk. Rather than simply imposed on a supposedly pliable public, its discourse 


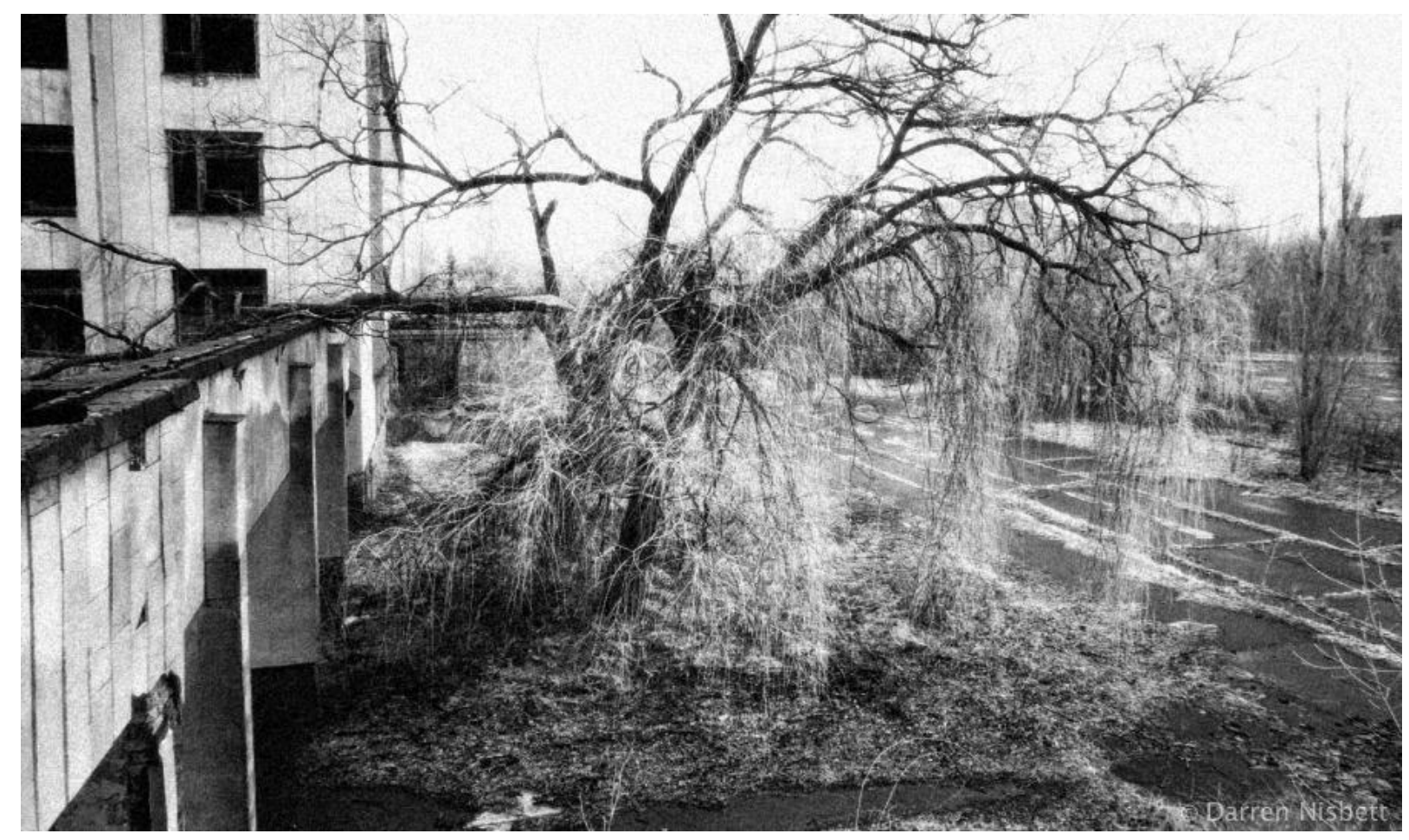

'Weeping Tree' 
seems to emerge from constant 'definitional struggles' between stakeholders over the very nature of these risks (Beck 1992). Kath Weston (2011) describes how in the after-math of the Fukushima nuclear disaster, radiation risks did not only become the subject of definitional struggles over the interpretation of knowledge, but also of what she calls 'techno-struggles' over the production of knowledge, as worried Japanese citizens began to question information released by the government and built Geiger counters to measure radiation themselves.

At the Symposium, scientists would define radioactivity to me mostly in direct response to what they considered public fears of radioactivity:

People think immediately about fish with three eyes!

Even the word 'radioactivity' scares people. If you say you can measure radioactivity, they think it's contaminated...

They would then go on to downplay radiation risks by comparing human-induced radiation to natural background radiation or to other allegedly bigger risks.

\section{POLLUTION BELIEFS}

While radiation might be real in the sense of material, its reality status (Adam, 1996) - as dangerous, desirable, risky, polluting or natural - arises in a process of competition, conflict and negotiation among different actors: scientists, publics, politicians and members of industry.

Here we can draw insights from Mary Douglas' famous framing of dirt as 'matter out of place' $(1966,2002)$ : Pollution beliefs, she argued, are physical boundaries drawn to distinguish between the moral and immoral and, as such, reflect a particular social order (Idem: 36). In later work, however, she refused to extend this argument to scientific claims $(1982,1999)$. Still, as I will show, when and for whom radioactive matter comes to be considered 'out of place' reflects value orientations rather than facts.

For opponents of nuclear technologies human-induced radiation has come to embody in its invisibility both pollution and danger. It is matter out of place, or even more so, matter that should not have been created and released by humans in the first place. For them, it has taken on strong moral significance too: Nuclear risk, symbolic of the problems of contemporary society, emerged as the flagship of the environmental movement in the 1970s (Strydom 2002: 22).

However, during the Symposium, when delegates discussed human-induced radiation, terms like pollution or contamination were used only to denote extreme, 'highexposure' scenarios. They casually spoke of radionuclide behaviour in terrestrial ecosystems, radioactive discharg- es or routine emissions. They discussed the effects and impacts of radionuclides on people and the environment rather than their harm. In other words, it became clear that when human-induced radiation is measured by scientists in the environment, it is not necessarily classified by them as pollution or contamination. Where are these boundaries drawn? Douglas and Wildawsky describe what they call 'technical' or 'objective' pollution as 'some harmful interference with natural processes’ (1982: 36). In international environmental legislation, pollution is also commonly defined with reference to 'harm' (Warren 1993). Scientific definitions of radioactive pollution thus partly depend on shifting, subjective categories of 'the natural' or pre-polluted, as well as of 'harm'.

\section{MUTANT ECOLOGIES}

Everyone, everywhere, is exposed to 'background radiation'. Although the exposure differs per geographical location, we get irradiated from naturally occurring radionuclides in the soil, in our diets, in the air; we are exposed to cosmic rays and to radiation emitted by certain types of rocks. But background radiation is not only 'natural': In the UK about $15 \%$ of the background radiation comes from cumulative effects of industry: in the majority from medical applications of radioactivity, followed by the residues of nuclear disasters and nuclear weapon tests, and operating nuclear power plants. This low-level 'background exposure' to radiation, partly caused by humans and continuing to rise, is possibly already changing the genetic structure of plants, animals, and people. Current work on the consequences of the Fukushima disaster found mutations among birds and butterflies, at levels of exposure 'way below anything we'd expect from the literature', one informant tells me: 'If they are correct, that might change all the protection criteria'.

Mutations can lead to irreversible evolutionary change, cancer, deformities and so-called 'genetic noise' that neither improves nor injures the organism but does affect future generations (Masco 2006: 301). It is 'a specific kind of break that reinvents the future' (Idem). Mutagenic processes blur familiar analytical dichotomies such as nature-culture, subject-object, human-animal and natural-artificial. What does this mean for 'environmental protection'? What counts as 'harm' when we speak about mutations, and what is acceptable? Perhaps what is at stake here is no longer the protection of nature but 'the choice of what sort of nature and society we want' (Hajer 1996: 259).

\section{UNKNOWABLE FUTURES}

To develop environmental regulations and safety standards, scientists are required to predict future 'harm' caused by human activities. This is problematic not only because what constitutes 'harm' is open to debate, but also because scientific innovation by definition cre- 
ates 'unknowable futures', as time theorist Adam writes (1996: 95-6). While mechanistic knowledge is required to devise new technologies, the knowledge required to study and predict their real-world impacts is of a different kind: both natural and social processes are networked, non-linear and as such inherently unpredictable (Adam 1993). The result is that 'our predictive knowledge falls behind the technical knowledge which nourishes our power to act', as philosopher Hans Jonas asserts (1974: 10). This turns our world into a living laboratory in which new technologies come into use and new industries roll out with little pause, unanticipated consequences bouncing back at us further down the line.

Paradoxically, while knowledge about the future is more and more reduced to the present, the effects of activities extend more and more into the future. For example, a radionuclide never ceases to be radioactive, however slightly. Since we cannot usefully talk about the 'life' of a radioactive source, the concept of 'half-life' is used: the time it takes for its level of radioactivity to fall by half. For example, an average nuclear power reactor releases varying amounts of tritium, radiocarbon (C-14) and Plutonium-239 into the environment, with half-lives of 12 years, 5,700 years and 24,400 years respectively. Equally, spent nuclear fuel can remain radioactive for at least 10,000 years, or even 250,000-500,000 years if the fuel contains plutonium (Fairlie 2011). At the symposium, one presenter discussed the environmental risk assessments undertaken for a permanent burial facility for nuclear waste in Finland. There it was decided to work with a time-scale of 10,000 years, as beyond that, it was 'just guessing'.

Scientists are asked to represent a future they cannot access empirically. On the basis of experiments and environmental monitoring of irradiated areas, they try to predict future effects through models, which enable them to coin certain safety thresholds for the release of radionuclides in a particular locality. A French marine biologist explained to me that, in the laboratory, his team conducts experiments 'in which we have only one parameter that is changing, which is the stressor, the polluter.' Ethnographies of laboratory practices confirm that scientists tend to study controlled, cleaned and purified phenomena about which models can be more easily made (Latour \& Woolgar 1979, Knorr-Cetina 1983). As such, experiments cannot account for all the interactions and different stressors in the environment, including, for example, the synergistic effects of radionuclides with other (chemical) particles.

Mutagenic effects also escape from the scientific gaze, due to empirical science's limited material, spatial and temporal focus: in lab experiments and ecological fieldwork, predictions of the future are generally formed through an analysis of causes and effects, on the basis of what observably happened in the past. Mutagenic effects, however, often only manifest themselves in our bodies and in eco-systems long after the harm has been done. Here links between causes and effects are hardly detectable. Occurring far away from the source in time and space, field sampling cannot fully capture radiation effects either. As such, embodied in latent processes, future effects are denied reality status by empirical science (Adam \& Groves 2002). They are real but not tangible; they are underway but not yet materialized into empirically accessible phenomena (Idem).

\section{UNCERTAINTY \& HUMILITY}

My informants often refused to give their personal opinion on the unpredictable, long-term effects of radiation induced by nuclear technologies:

As a scientist, I cannot say that the impact of radioactivity which is added to the natural radiation in the natural environment is actually killing species. I can't say that because we can't see that!' [My emphasis]

The nature of radioactive ecologies seems to challenge the expectations of science held by the public and policymakers alike. Nature-culture configurations characterised by mutations defy any take on nature as knowable and manageable - if indeed it ever was. Mutant ecologies are unpredictable and uncontrollable. As such mainstream environmentalism's focus on physical and demonstrable 'limits' of the environment, trespassed by humans, hits the wall of scientific uncertainty.

Jasanoff observes that in fact most questions regulators ask of scientists cannot adequately be answered by science (1990: 7). The scientists I interviewed indeed admitted that the environmental assessments they undertook and the numerical criteria they provided to policymakers were clouded in uncertainty. At the same time, they stressed they had to answer to demands for facts by regulators and other authorities. One informant working for the International Commission for Radiological Protection told me they will eventually start adding uncertainty ranges to the numerical protection criteria they develop. He added:

But the difficulty is: how do you interpret that information? [Grinning] We always laugh. We say that regulators - bearing in mind I used to be one - wear their simple hats: 'Yes! No answers!' Providing numbers is a much clearer way to be able to explain to people this is safe and this isn't safe.

Science fixes our attention on the knowable. The combination of scientific uncertainty and demands for facts can allow for inaction on potentially destructive 'externalities' of human activities: A lack of conclusive evidence on any long-term consequences is all too readily taken as a legitimation for business as usual. Jasanoff argues that what our age needs is humility: humility 'about both 
'Menace on the Horizon'

All images courtesy of Darren Nisbett and used with his kind permission.

For more images and information visit http://www.darkoptics.net/

These photos are from the UK photographer's series 'Chernobyl: Alienation'. Nisbett visited in 2011, 25 years after the Chernobyl nuclear accident, the $2,600 \mathrm{~km}^{2}$ abandoned Chernobyl Exclusion Zone in the Ukraine. Pripyat, now a ghost town, was built in 1970 as a home to the thousands of people that worked at and around the power plant. The day after the explosion, the inhabitants were given two hours to pack their belongings and were told that they would be away for a matter of days. But they would never return to their homes. 
the limits of scientific knowledge and about when to stop turning to science to solve problems' (2007: 33). Practicing humility would lead 'policy-makers to re-engage with the moral foundations for acting in the face of inevitable scientific uncertainty' (Idem).

My informants did not see scientific uncertainties about impacts as a barrier to the use of nuclear technologies. One informant who worked and researched in environmental management in the UK, told me:

We're left in a situation where we have to make decisions now because things are being developed now, things are happening now (...) Uncertainty can't stop you from taking decisions, because otherwise, development would stagnate completely. (His emphasis)

Most of my informants were outspokenly in favour of nuclear energy and technologies. They often held a utilitarian stance: nuclear technologies were simply a case in which the benefits outweighed the risks, and over-caution should not hinder 'development'.

\section{CONCLUSION}

If science cannot reliably predict the long-term effects of the build-up of human-induced radioactive particles in the environment, questions arise: What level of harm and risk to both human and environmental health is acceptable? What kind of environment and what kind of future do we want, or ought, to create?

Perhaps what is needed first is recognition that the process of establishing safe and acceptable levels of radiation is indeed a subjective one. Scientists cannot adequately predict the long-term impacts of nuclear technologies, and questions of what we ought to be protecting bring us from the empirical into the normative realm. Representing radiation risk is, as any act of representation, a political act. Once we recognise that, we can address decisions about the use of nuclear technologies more openly and more humbly. It is time to ask: who should be representing radiation risk, the environment and the future? This is thus not only a question of access to knowledge, but also of the allocation of agency and authority in decision-making processes. 佔

\section{ACKNOWLEDGEMENTS}

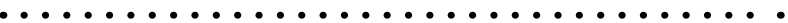

With thanks to my honours dissertation supervisor Rebecca Marsland. 
Adam, B. (1993) 'Time and Environmental Crisis: An Exploration with Special Reference to Pollution.' Innovation in Social Science Research. 6: 99-413.

Adam, B. (1996) 'Re-vision: the centrality of time for an ecological social sciences perspective.' Pp. 84-104 in S. Lash, B. Szerszynski, B. Wynne (eds.) Risk, Environment and Modernity: Towards a New Ecology. London: Sage.

Adam, B. \& Groves, C. (2002) Future Matters: Action, Knowledge, Ethics. Leiden \& Boston: Brill.

Beck, U. (1992) Risk Society: Towards a New Modernity. London: Sage.

Douglas, M. (1966, 2002) Purity and Danger: An Analysis of Concepts of Pollution and Taboo. London: Routledge.

Bird, W. (2012) 'As Fukushima Clean-up Begins, Long-term Impacts are Weighed.' Yale Environment 360 [online] Available at http://e360.yale.edu/feature/ as_fukushima_cleanup_begins_longterm_impacts_are_ weighed/2482/ [Accessed 28 October 2012] .

Douglas, M. \& Wildavsky, A.B. (1982) Risk and Culture: An Essay on the Selection of Technical and Environmental Dangers. Berkeley: University of California Press.

Douglas, M. (1999) 'Environments at risk.' Pp. 230-49 in Implicit Meanings: Selected Essays in Anthropology. London: Routledge.

Fairlie, I. (2011) Radiation Risks: An Independent Review. [online] Available at http://www.ianfairlie.org/ new-radiation-book/ [Accessed 09 November 12].

Grove-White (1993) 'Environmentalism: a new moral discourse for technological society?' Pp. 31-43 in K. Milton (ed.) Environmentalism: The view from Anthropology. London: Routledge.

Grozman, E. (2011) 'Radioactivity in the Ocean: Diluted, But Far from Harmless.' Yale Environment 360 [online] Available at http://e360.yale.edu/feature/radioactivity in_the_ocean_diluted_but_far_from_harmless/2391/ [Accessed 28 October 2012].

Hajer, M.A. (1996) 'Ecological modernisation as cultural politics.' Pp. 246-69 in S. Lash, B. Szerszynski, B. Wynne (eds.) Risk, Environment and Modernity: Towards a New Ecology. London: Sage.

Jasanoff, S. (1990) The Fifth Branch: Science Advisers as Policymakers. Cambridge, Mass.: Harvard University Press.
Jasanoff, S. (2007) 'Technologies of Humility.' Nature. 450 (1): 33 .

Jonas, H. (1984) The Imperative of Responsibility - In Search of an Ethics for the Technological Age. Chicago: University of Chicago Press.

Knorr-Cetina, K. (1983) 'The ethnographic study of scientific work.' Pp. 115-140 in K. Knorr-Cetina \& M. Mulkay (eds.) Science Observed. London: Sage.

Latour, B. \& S. Woolgar (1979) Laboratory Life: The Social Construction of Scientific Facts. Beverly Hills: Sage Publications.

Latour, B. (2004) Politics of Nature: How to Bring the Sciences into Democracy. Cambridge, Mass.: Harvard University Press.

Masco, J. (2006) The Nuclear Borderlands: The Manhattan Project in post-Cold War New Mexico. Princeton, N.J.: Princeton University Press.

Strydom, P. (2002) Risk, Environment and Society: Ongoing Debates, Current Issues and Future Prospects. Buckingham: Open University Press.

Weston, K. (2011) Seizing the Means of Perception: Technostruggle and the Fukushima Radiation 'Problem'. Seminar Social Anthropology, 28 October 2011, University of Edinburgh.

Warren, L. (1993) 'The Precautionary Principle: Use with Caution!' Pp. 95-111 in K. Milton (ed.) Environmentalism: The view from Anthropology. London: Routledge.

Yearly, S. (1993) 'Standing in for Nature: The Practicalities of Environmental Organisations' Use of Science.' Pp. 59-73 in K. Milton (ed.) Environmentalism: The View from Anthropology. London: Routledge. 